\title{
ACCESSIB ILITY ANDUSABILITY OF LANDSAT 8 DATA FOR THE PURPOSE OF SATELLITE-DRIVED BATHYMETRY OF THE SOUTH BALTIC NEAR-SHORE WATERS ON THE EXAMPLE OF GULF OF GDAŃSK
}

\author{
Karolina Zwolak*1(D), Łukasz Marchel*2(D, Marcin Skóra*3 (D), \\ Radosław Przybysz*4 (D), Rafał Jóźwiak*5 ${ }^{\mathbb{C}}$, Kinga Tomaszewska** (D) \\ * Polish Naval Academy, Faculty of Navigation and Naval Weapons, Śmidowicza 69 Str., 81-127 \\ Gdynia, Poland; e-mail: k.zwolak@amw.gdynia.pl, l.marchel@amw.gdynia.pl, m.skora@amw.gdynia.pl, \\ r.przybysz@amw.gdynia.pl, r.jozwiak@amw.gdynia.pl; ORCID ID: 10000-0002-5540-4710, 20000- \\ -0003-1692-9175, 30000-0003-0309-2185, 40000-0002-1240-1261, 50000-0001-7513-6672 \\ ** 3rd Ship Flotilla, Rondo Bitwy pod Oliwą 1 Str., 81-103 Gdynia, Poland; e-mail: k_tom07@gmail.com; \\ ORCID ID: 0000-0002-9564-1155
}

\begin{abstract}
The paper presents the analysis of accessibility and usability of Landsat 8 Satellite Imagery for the purpose of Satellite Derived Bathymetry (SGB) products generation of the area of near-shore waters of the Polish coast. General assumptions of the SDB, Landsat program and factors affecting the products generation process have been described in details. Examples of SDB results, generated using both GIS software and Matlab, are presented on the example of chosen areas of Gulf of Gdańsk. The advantages and disadvantages of the SDB method are presented in the discussion and conclusion part with the proposed directions for the future works.
\end{abstract}

Keywords:

Satellite Derived Bathymetry, Landsat 8, bathymetric survey.

Research article

(c) 2020 K. Zwolak, Ł. Marchel, M. Skóra, R. Przybysz, R. Jóźwiak, K. Tomaszewska This is an open access article licensed under the Creative Commons Attribution-NonCommercial-NoDerivatives 4.0 license (http://creativecommons.org/licenses/by-nc-nd/4.0/) 


\section{INTRODUCTION}

As soon as people began to exploit maritime areas, initially for transport purposes, it was immediately necessary to obtain a reliable information about what is under the water surface to ensure the safety of navigation. Shoals, rocks or wrecks of the first sunken ships have always posed a threat to vessels. Then ideas began to appear on how to get this information. Over the years of experience, these methods have been improved, and today it is possible to choose from many available, depending on the user's needs and capacity. Single and multibeam echosounders or interferometric side scan sonars provide mariners with the accurate data about seafloor depths at literally all the possible depth ranges, although its manufacturing and operation is labor-intensive and extremely expensive. Further shallow water can be covered by LiDAR devices, but airborne equipment on traditional aircraft is expensive to use and not widely available.

At the same time the satellite technology has been developed for various purposes, including positioning and surveillance applications. Later, the possibility of obtaining information about depths of any waterbody without the need of direct measurements in these places seems to be a promising vision of the future hydrography. To do this, only access to photos taken by satellites and the ability to process the image into a bathymetric map product would be required. The current level of advancement and continuous development of a technology is able to partially provide these needs. However, there are still some limitations that neither man nor any device can overcome. Therefore, we are talking mainly about atmospheric conditions and the properties of the sea water, which may have a negative impact on the possibility of using satellite images to create accurate bathymetric maps.

\section{LANDSAT 8 IMAGERY DATA}

Landsat satellite system was created in early 70s of the last century, as a part of a cooperation between the two American leading research centers - NASA (National Aeronautics and Space Administration) and USGS (United States Geological Survey). Over the decades, the system has been modernized by introducing the satellites numbered according to the chronology of the process of their location on the near-polar orbit. The operational part of the system is now composed of one satellite, designed for remote data acquisition, and the Earth-based control station. Images 
are collected in several sub-ranges of the electromagnetic spectrum. The full spectrum used by Landsat 8 is divided into 11 sub-bands [3]. Tab. 1 shows the sub-ranges used by the Landsat 8 Operational Land Imager (OLI) and Thermal Infrared Sensor (TIRS).

Tab. 1. Landsat-8 sensor OLI \& TIRS bands [3]

\begin{tabular}{|l|l|l|l|}
\hline \multicolumn{4}{|c|}{ Landsat-8 sensor OLI \& TIRS bands $(\boldsymbol{\mu m})$} \\
\hline Sub-range & Description & Wavelength $(\boldsymbol{\mu m})$ & Resolution $(\mathbf{m})$ \\
\hline Band 1 & Coastal / Aerosol & 0.435 to 0.451 & 30 \\
\hline Band 2 & Visible blue & 0.452 to 0.512 & 30 \\
\hline Band 3 & Visible green & 0.533 to 0.590 & 30 \\
\hline Band 4 & Visible red & 0.636 to 0.673 & 30 \\
\hline Band 5 & Near-infrared & 0.851 to 0.879 & 30 \\
\hline Band 6 & Short wavelength infrared & 1.566 to 1.651 & 30 \\
\hline Band 7 & Short wavelength infrared & 2.107 to 2.294 & 60 \\
\hline Band 8 & Panchromatic & 0.503 to 0.676 & 15 \\
\hline Band 9 & Cirrus & 1.363 to 1.384 & 30 \\
\hline Band 10 & Long wavelength infrared & 10.60 to 11.19 & 100 \\
\hline Band 11 & Long wavelength infrared & 11.50 to 12.51 & 100 \\
\hline
\end{tabular}

Information is processed according to the selected sub-bands for the needs of a cartography, an agriculture, an assessment of changes on the Earth, geology and many others. Images are available for free and can be downloaded from the official USGS website (https://earthexplorer.usgs.gov). User interface is presented on fig. 1.

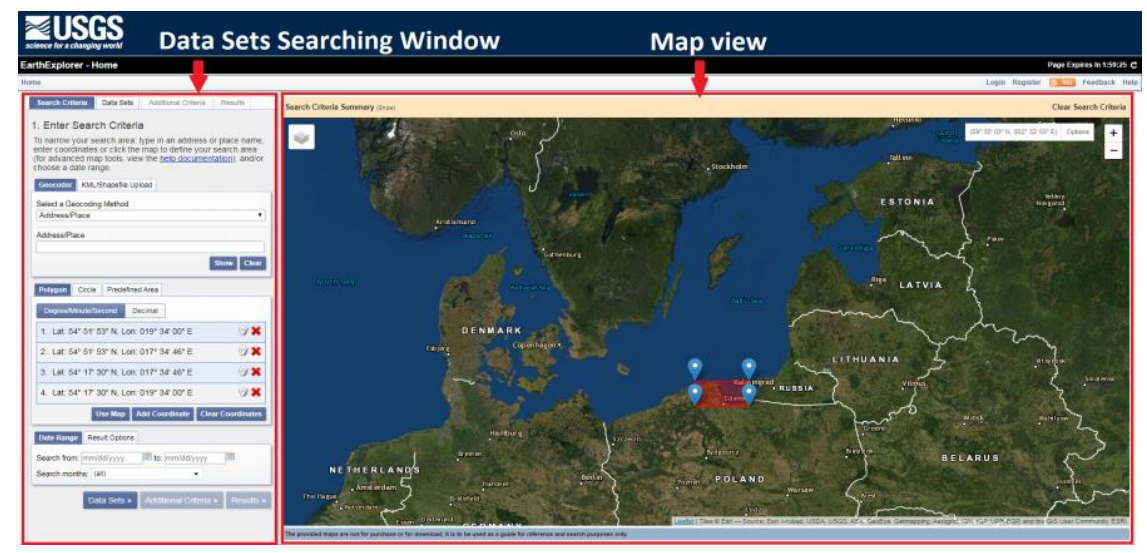

Fig. 1. User interface [https://earthexplorer.usgs.gov/] 
The satellite works at an altitude of $705 \mathrm{~km}$ and is powered by solar panels. The batteries power the satellite when there is no solar energy input. The main orbital parameters are: the average period is 99 minutes and the inclination is equal to 98.2 degrees. The satellite is equipped with two types of sensors: Operational Land Imager (OLI) and Thermal Infrared Sensor (TIRS). Sensors can work independently of each other. OLI is the main imaging instrument installed on Landsat 8. This sensor records the imagery in 9 sub-ranges of visible and invisible bands. The resolution is $30 \mathrm{~m}$ or 15 meters, depending on the band. The OLI type sensor has been designed to function for 5 years from the date of commissioning. Thermal Infrared Sensor is the second sensor installed on the satellite. TIRS gathers images of the Earth in sub-range spectrum emitted by the Earth's Surface according to the temperatures of particular areas. Landsat 8 uses two types of radio frequency antennas: the S-band is used to control the satellite and X-band used to send imagery to the control station [3].

There are a number of products derived from the collected imagery and released by the USGS for end-users. Data used in this paper are downloaded from 'Landsat 8 OLI/TIRS C1 Level-1' subset of 'Landsat Collection 1 Level 1'.

\section{CHARACTERISTICS OF POLISH COASTAL WATERS IN TERMS OF SATELLITE IMAGERY ACQUISITION}

Satellite imagery acquisition of coastal water areas for the purpose of bathymetry assessment is mostly affected by two factors: weather conditions and water clarity.

According to [6] Baltic Sea watermasses are characterized by high levels of suspended matter and Colored dissolved organic matter (CDOM), with the origin of nearby land areas. The suspended material strongly influences the Sun light penetration. Brownish color characterizes the large amount of CDOM in the Baltic waters. The inversion from optical measurements into water properties, due to the fact of multi-componential water characteristic, cannot necessarily be unique It can highly affect the accuracy of image analysis based methods results [6]. Similar analysis are presented in [15].

Cloudiness is the weather condition, which in many cases disqualifies the acquired image from further analysis. For the Polish coast the cloudiness is significant throughout the year. From March to September, averagely 6/10 of the sky is covered 
with clouds. May and June are the sunniest months. In the rest of year months the average cloud cover ratio is $7 / 10$ and in December $8 / 10$. The average annual number of cloudy days is $112-160$ and sunny days is $22-47$. Cloudy days in the coastal zone usually occur from October to March and sunny days from April to September $[1,4]$.

Fig. 2 presents the percentage of cloud cover and the sun elevation for all the Landsat 8 images collected over the Gulf of Gdańsk, from 2014 to 2019 . The data from all the images with the cloud coverage less than $10 \%$ have been summarized in tab. 2 Note, that only 16 images from 121, can be used for the wider analysis of Earth surface, the rest is partially or fully covered by clouds.

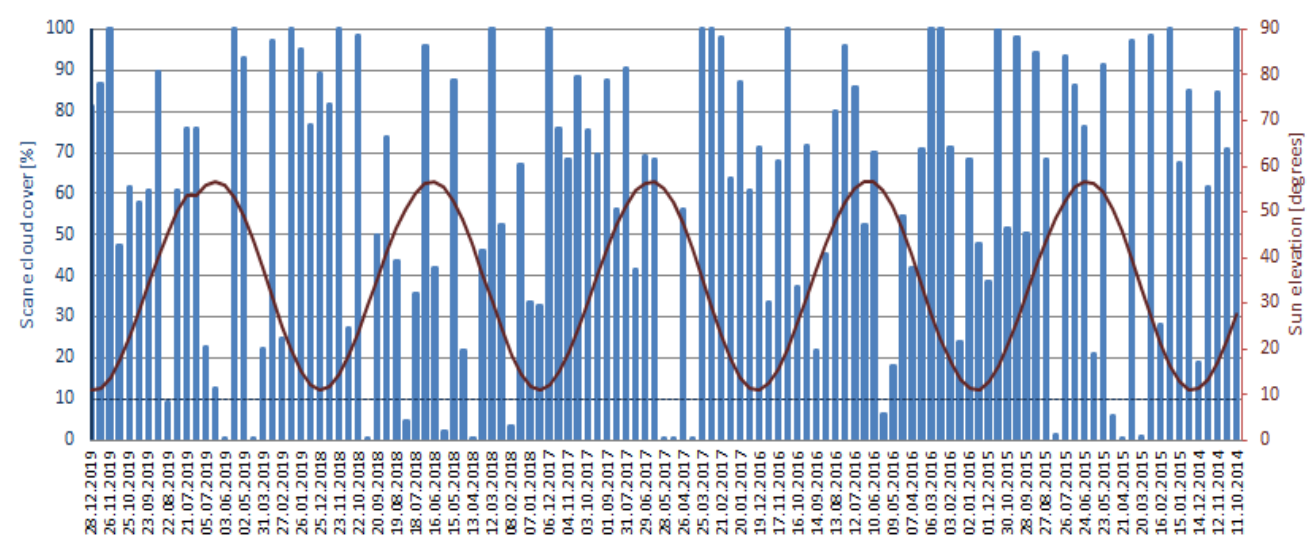

Fig. 2. The percentage of cloud cover (blue) and the sun elevation (dark red), for Landsat 8 images collected over the Gulf of Gdańsk, from 2014 to 2019

Tab. 2. The summary of all the images with the cloud coverage less than $10 \%$ collected over the Gulf of Gdańsk, from 2014 to 2019

\begin{tabular}{|c|c|c|c|c|c|c|c|c|}
\hline Date & $\mathbf{2 0 . 0 3 .}$ & $\mathbf{2 1 . 0 4}$. & $\mathbf{0 7 . 0 5}$. & $\mathbf{1 1 . 0 8}$ & $\mathbf{2 5 . 0 5}$. & $\mathbf{1 0 . 0 4}$ & $\mathbf{1 2 . 0 5}$ & $\mathbf{2 8 . 0 5 .}$ \\
& $\mathbf{2 0 1 5}$ & $\mathbf{2 0 1 5}$ & $\mathbf{2 0 1 5}$ & $\mathbf{2 0 1 5}$ & $\mathbf{2 0 1 6}$ & $\mathbf{2 0 1 7}$ & $\mathbf{2 0 1 7}$ & $\mathbf{2 0 1 7}$ \\
\hline Cloud cover [\%] & 0.95 & 0.09 & 5.99 & 1.64 & 6.28 & 0.04 & 0.06 & 0.02 \\
\hline Sun elev. [deg] & 33.45 & 45.64 & 50.59 & 48.71 & 54.77 & 41.89 & 52.05 & 55.19 \\
\hline \multirow{2}{*}{ Date } & $\mathbf{0 8 . 0 2}$. & $\mathbf{1 3 . 0 4}$. & $\mathbf{3 1 . 0 5}$. & $\mathbf{0 3 . 0 8}$. & $\mathbf{0 6 . 1 0}$ & $\mathbf{1 6 . 0 4}$ & $\mathbf{0 3 . 0 6}$. & $\mathbf{2 2 . 0 8 .}$ \\
& $\mathbf{2 0 1 8}$ & $\mathbf{2 0 1 8}$ & $\mathbf{2 0 1 8}$ & $\mathbf{2 0 1 8}$ & $\mathbf{2 0 1 8}$ & $\mathbf{2 0 1 9}$ & $\mathbf{2 0 1 9}$ & $\mathbf{2 0 1 9}$ \\
\hline Cloud cover [\%] & 3.50 & 0.08 & 2.27 & 4.63 & 0.03 & 0.04 & 0.03 & 9.24 \\
\hline Sun elev. [deg] & 18.71 & 42.90 & 55.50 & 50.71 & 29.44 & 43.9 & 55.9 & 45.8 \\
\hline
\end{tabular}

The ice cover can also affect the usefulness of satellite acquired images, although shipping conditions in the South Baltic are favorable. In open areas in $75-90 \%$ of all winters ice phenomena do not occur. Along Polish coasts, ice is not present in $50-75 \%$ of all winters $[1,4]$. 


\section{BATHYMETRY ASSESSMENT BASED ON THE SATELLITE IMAGERY}

There is a number of works mentioning the Satellite Derived Bathymetry, as one of the ways to obtain information about the depths of waters. They are presented in this section. The authors of these works already in the introductions of their publications clearly indicate the possibility of using satellite bathymetry only in the shallow waters of coastal areas, which is characteristic for all the bathymetric measurement techniques based on the Sun light penetration, due to the fast attenuation in the water column.

Theoretical fundamentals for Satellite Derived Bathymetry have been built by David Lyzenga, in 1978 [7]. Three years later he published the developments of his methods [9]. In his considerations he took into account both photos taken from one of the Landsat satellites and obtained using a multispectral scanner located on an aircraft. After proper treatment and comparison with the existing maps of the examined area, he found an advantage in the accuracy of images from the scanner over satellite. As the reason he gave, among others, the fact that the quality of satellite images depends on weather conditions, especially cloud cover. Sometimes a cloud cover completely prevents further use of images, as well as errors in the operation of the algorithm creating the final bathymetric product. However, the SDB, assessed as a trade-off between the map accuracy and the method availability, proved its validity as a reconnaissance tool. His thesis have been also developed in his and his co-authors later publication [8].

The author who also noticed the dependence of bathymetric map accuracy on meteorological conditions is William Philpot [13]. However, he paid more attention to the hydrology of the study area than the impact of the atmosphere. In his work, he developed research results indicating that satellite bathymetry will only fulfill its role in places where the conditions in the water are characterized by low variability. We are talking here mainly about the mixing of water layers, the occurrence of flowering vegetation in different seasons and the movement of bottom sediments. All these factors affect the occurrence of errors during photo processing due to the different reflecting properties of different types of seabed or plant density. Then, the reflected wave returning to the satellite will not correctly indicate the depth in the investigated water.

The most fundamental paper for the Satellite Derived Bathymetry is [14]. The paper describes the modern methodology, applied nowadays for depth determination applications using satellite imagery of different types. 
A lot of works in the field of Sattelite Bathymetry have been done by the team lead by Shachak Pe'eri. They assessed SDB methods in various conditions and published their results in [10-12].

Note, that in many cases in this paper the term 'bathymetric product' is used instead of 'bathymetric map' or 'chart'. Although the difference between map and chart is obvious in the nautical literature, the 'product' may seem to be not understood. The reason to avoid the word 'map' is not to infer that the SDB truly depicts the real shape of the seafloor. There are such a number of restrictions, under SDB algorithms are utilized, so the effect should be understood as an algorithm result only - means a product - not a map.

Bathymetric product generation procedure starts with extraction of the subset of usable images from the complex dataset downloaded from the Landsat imagery depository. Images must be selected based on time, we are interested in, but also based on the environmental conditions, which includes the cloud coverage and sun glint. Recommended SDB bands from Landsat 8 are presented in tab. 3.

Tab. 3. Landsat 8 bands recommended for the SBD procedure [5]

\begin{tabular}{|c|c|c|c|}
\hline Platform & Band & Image number in dataset & Wavelenght $(\boldsymbol{\mu m})$ \\
\hline \multirow{3}{*}{ Landsat 8} & Blue & 2 & $0.45-0.51$ \\
\cline { 2 - 4 } & Green & 3 & $0.53-0.59$ \\
\cline { 2 - 4 } & Infrared & 6 & $1.57-1.65$ \\
\hline
\end{tabular}

Downloaded imagery format (GEOTIFF) suggests using the Geographic Information System software. ArcMap 10.5.1 has been used for the image processing. Authors of [5] presents the tutorial of bathymetric products generation using ArcGIS. Setting up the workspace in ArcMap, importing the appropriate charts for reference and importing downloaded imagery (fig. 3a) are the parts of preprocessing before the whole procedure.

Infrared (IR) image is used for land/water separation. Profile Graph tool in ArcMap can be used for determining the value of threshold, separating the wet and dry areas, clearly visible on the infrared imagery. In case of Landsat 8 images, the threshold value is usually around 5500. The values corresponding to the pixels representing the water body are below 5000, while the highest values on land reach around 16000. The boundary between land and water is delimited by a very clear, rapid values difference. Generated matrix indicating water bodies is then used for water body extraction on remaining images (fig. 3b). 

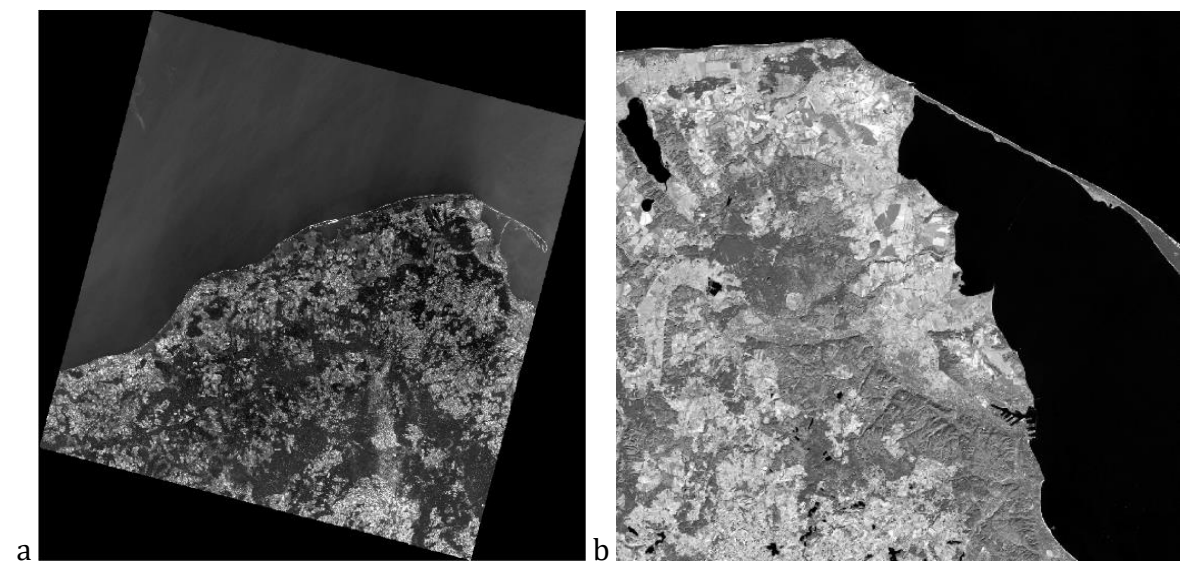

Fig. 3. (a) Blue and green bands uploaded into the ArcMap software (the last one on top); (b) Infrared band matrix used for water bodies extraction

Next step is derived from the ratio approach, presented in [14], which says that the actual depth at a given point is proportional to the ratio of natural logarithms of reflectance values of blue and green band at the corresponding pixel of the multispectral imagery (Equation 1):

$$
Z=m_{1} \frac{\ln \left(n R_{w}\left(\lambda_{i}\right)\right)}{\ln \left(n R_{w}\left(\lambda_{j}\right)\right)}-m_{0}
$$

where:

$m_{1} \quad$ - tunable constant to scale the ratio to depth;

$m_{0} \quad$ - the offset for a depth of $0 \mathrm{~m}$;

$R_{w}\left(\lambda_{i}\right)$ - reflectance values of blue band;

$R_{w}\left(\lambda_{j}\right)$ - reflectance values of green band;

$n \quad-$ a fixed constant for all areas, chosen to assure both that the linear response with depth will be produced and the logarithm will be positive under any condition.

The values of logarithms ratios $\left(\ln \left(n R_{w}\left(\lambda_{i}\right) / \ln \left(n R_{w}\left(\lambda_{i}\right)\right)\right.\right.$ creates the surface called the Bathymetry Algorithm Surface (here: the BA Surface - fig. 4). It's values are linearly proportional to the depths down to the specific depth, called the Extinction Depth; beyond that there is no linearity in the values-depths dependence. The Extinction Depth is characteristic for a particular area, depends on the optical properties of the water and determines the usability of Satellite Derived Bathymetry method for the analyzed region. 


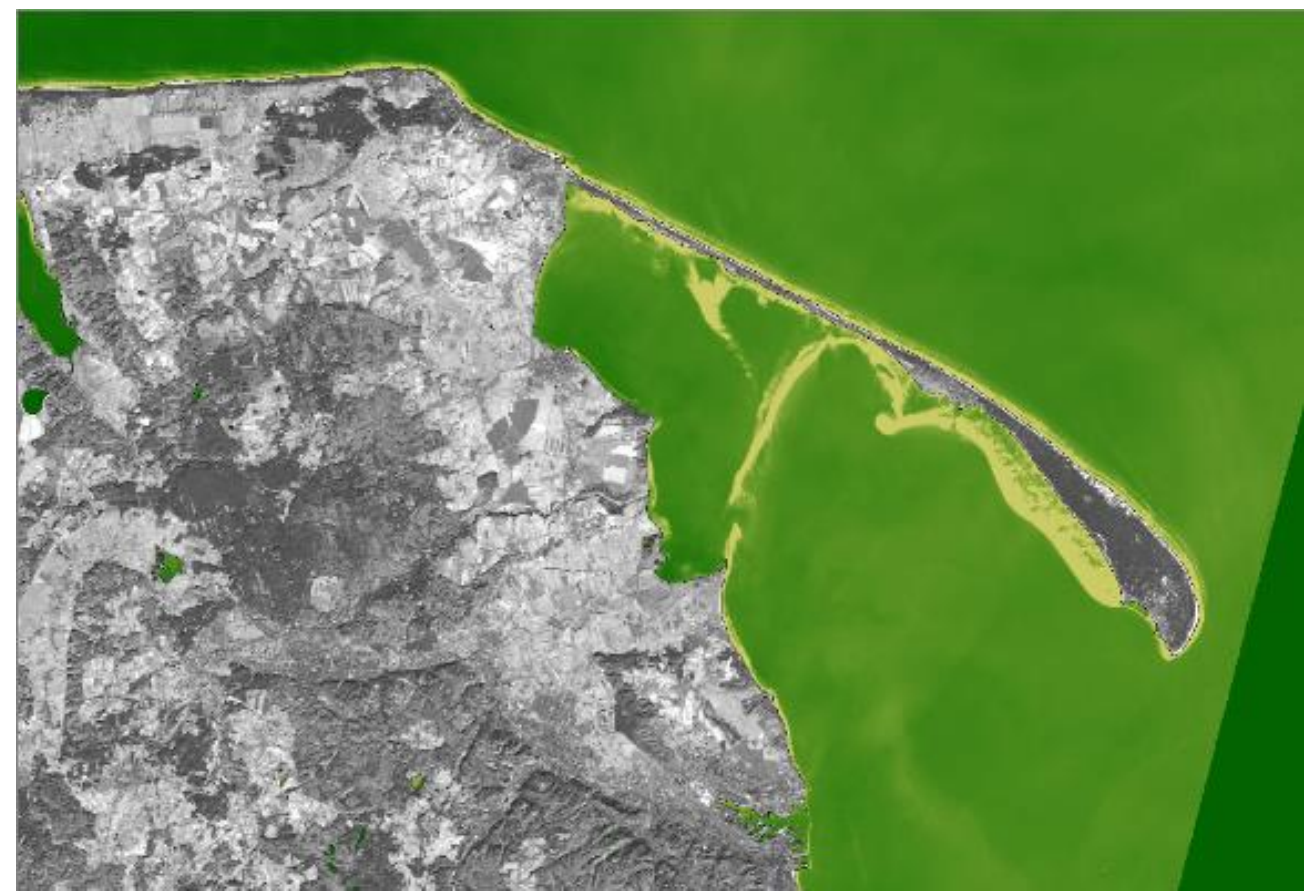

Fig. 4. Bathymetry Algorithm Surface in ArcMap

While the logarithms ratio values for each pixel are conducted from the imagery only, determining the $\mathrm{m}_{1}$ and $\mathrm{m}_{0}$ values requires the use of control points. Andrzej Chybicki in [2] uses the results of bathymetry measurements conducted on the profiles perpendicular to the coast line and the prevailing direction of isobaths, which provides the reference at various depths. This is very appropriate approach, although requires dedicated survey, conducted on the vessel capable of operating at very shallow depths. Another possibility is to use the survey conducted for general safety of navigation purposes and published in the form of ENC or nautical chart soundings or to use point cloud or grid data from those surveys, depending on the resources available for a specific area (fig. $5 \mathrm{a}$ ).

Bathymetric products are created region-wise; it means that the values from the specified basin are analyzed at once, by masking it by the polygon designed to include the depths from a specified range, from the shallowest possible to exceeding the expected Extinction Depth. The examples are presented in fig. $5 \mathrm{~b}$. 

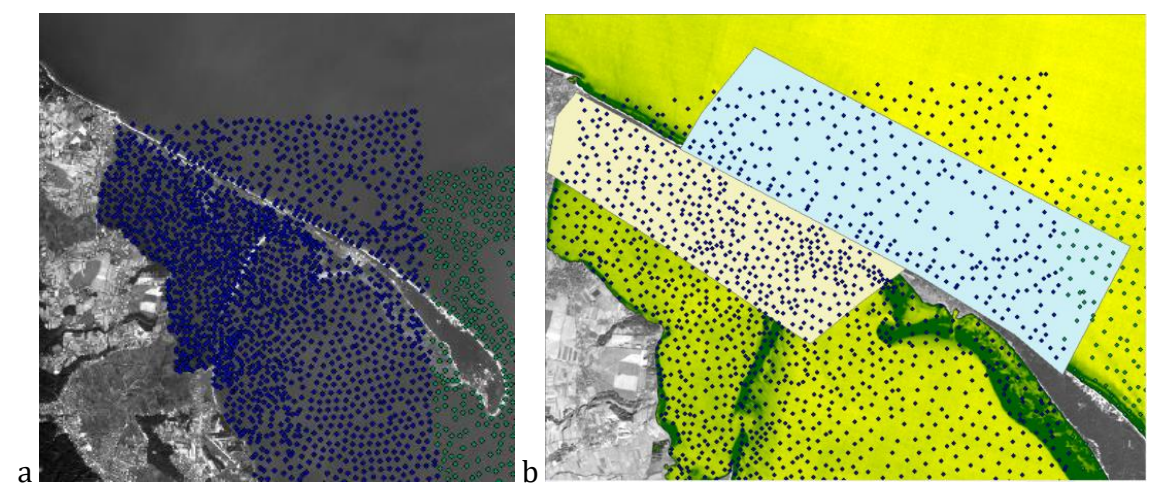

Fig. 5. (a) The locations of ENC soundings derived from the ENC cells produced by the Hydrographic Office of the Polish Navy; (b) Example polygons generated to extract depth data and compare with BA Surface

After plotting the reference depths against the corresponding values from the BA surface, we are able to estimate the Extinction depth, by determining the depth value on the plot, above which we are not able to observe the approximately linear dependency between plotted values (fig. 6a). The subset of data, below the Extinction Depth is used for SDB depth determination, by generating a trend line (fig. 6b). The Extinction Depth value assumed here for further analysis was $5 \mathrm{~m}$.
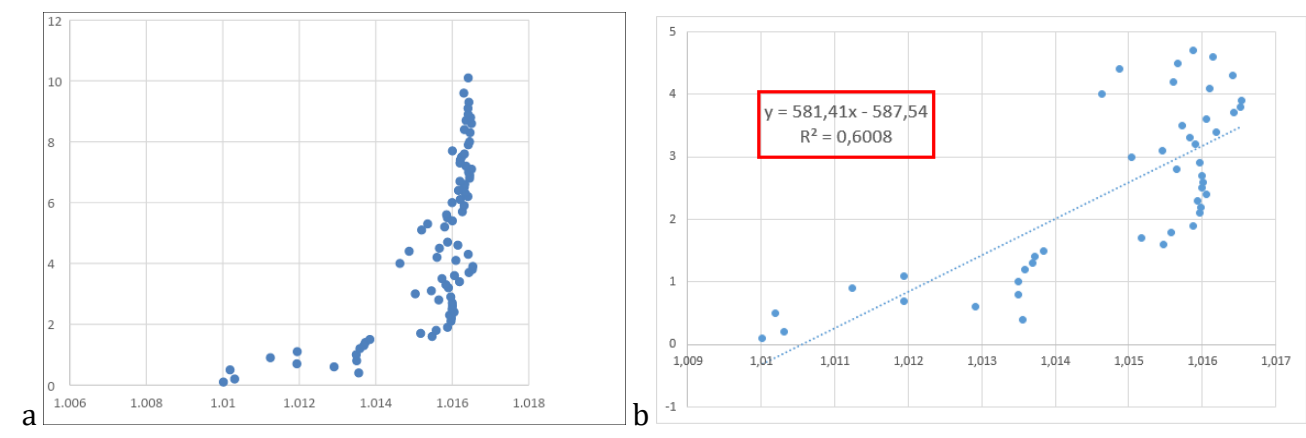

Fig. 6. (a) The reference depths plotted as a function of the corresponding values from the BA surface;

(b) The trend line with its coefficients, generated for the subset of data with linear dependency

By applying the gain and the offset coefficients according to Equation 1 to the BA surface, we are getting the Satellite Derived Bathymetry Product (SDB Bathymetry) and this is called the referencing operation. After limiting the results to the range within the Extinction Depth value, we can present the results in the form of a map (fig. 7). 


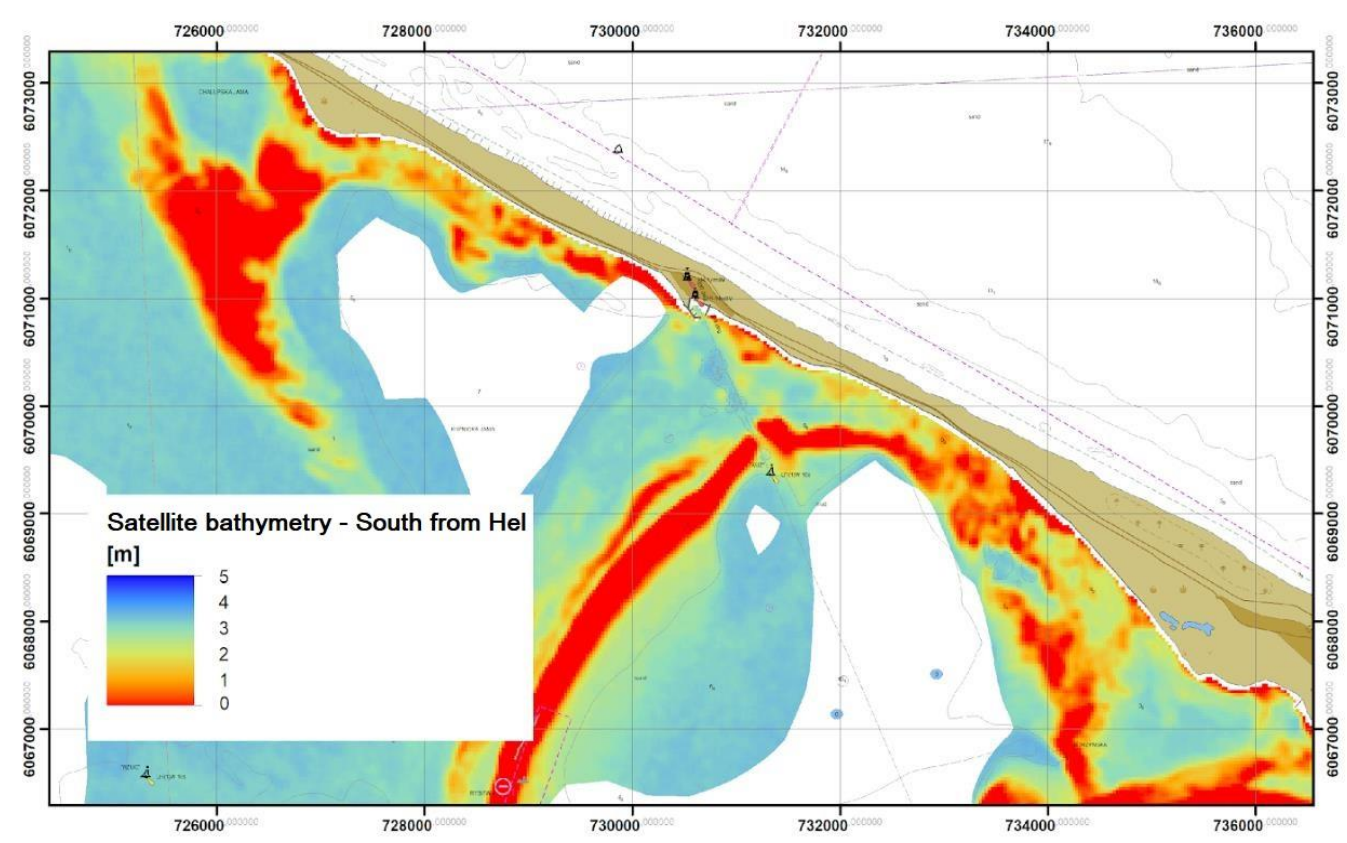

Fig. 7. The result of Satellite Bathymetry Algorithm — an example area, South to the Jastarnia harbour on the Gulf of Gdańsk

The full Satellite Bathymetry algorithm implementation is in fact a series of steps, which can be done in GIS software, but they can also be coded to automate all the stages of product generation. The application to automatically generate the surfaces has been written in Matlab and utilized for fast product generation of the series of images collected over the same area from 2015 to 2019. This allows us to observe the changes of the analyzed area over the chosen period of time. It was noticed that to observe only the fact of the changes, caused by sediment movements, it is enough to generate the BA Surfaces and compare them. The example is presented in fig. 8 . BA Surfaces have been presented in a grayscale. Dark areas indicate shallower depths. Isobaths on ENC are generated based on data from 2009. We can clearly see the conformity between color-indicated shallower areas with the isobaths from ENC on the images from 2015 to 2017. Later on, the sediments movement have been changing the general shape of the shoal, which can be observed on the generated imagery. 


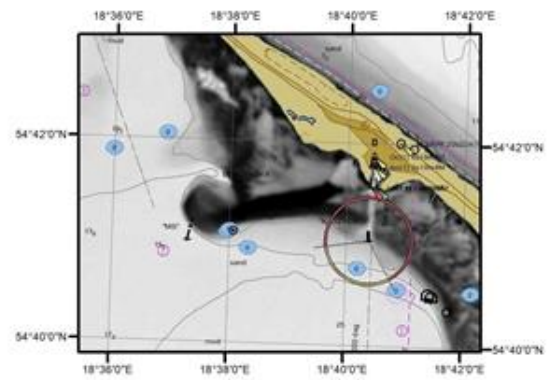

21.04.2015.

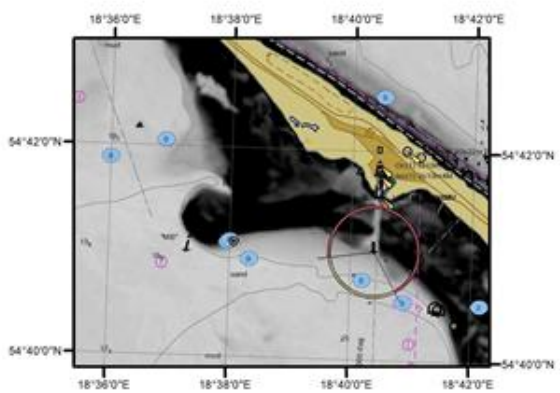

28.05.2017.

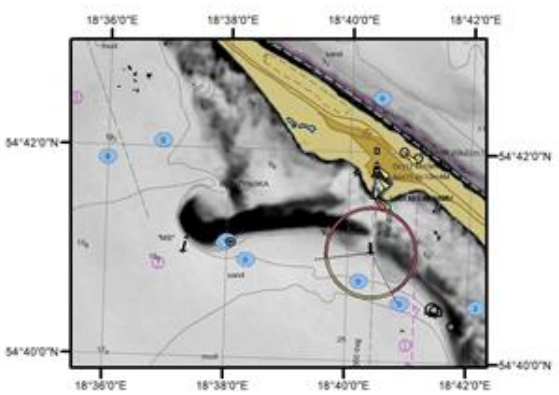

03.08.2018.

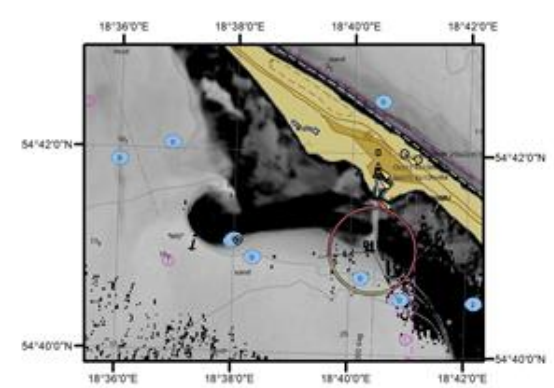

25.05.2016.

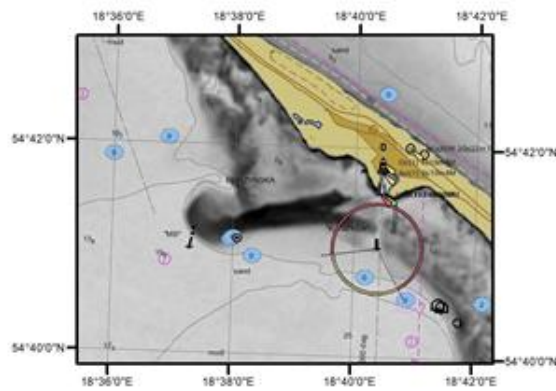

08.02.2018.

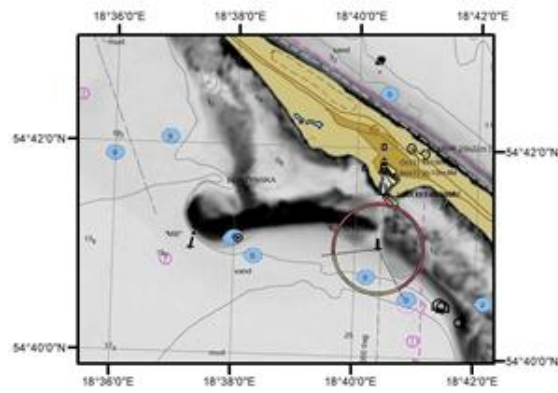

22.08.2019.

Fig. 8. BA Surfaces generated based on the Landsat imagery from 2015 to 2019

\section{DISCUSSION OF THE METHOD AND ITS POTENTIAL USE}

Bathymetric maps were compared with the data from electronic navigation charts. Using this method, it is possible to immediately compare the depths obtained using SDB with those obtained with data acquisition methods of hydrographical 
quality, for example using a multibeam echosounder. Such data is definitely more accurate and more reliable than satellite imagery derived bathymetry, so a comparison of the values on the maps will be carried out in relation to them, followed by an assessment of the suitability of bathymetric products from the satellite.

Often it can be seen that the bottom profile is arranged very similarly to the one determined using isobaths. Where there is a shallower area, there is indeed a color that indicates smaller depths.

Very often it can be noticed that satellite bathymetry tends to highlight values. In shallower places, according to the satellite map, the depth value is close to 0 , while in deeper places these values are excessively large. At the same time, the bottom shape variability trend is maintained. This fact indicates the possibility of using satellite maps for purposes that do not require specific values, but only estimates or the detection of changes in time.

Looking at the satellite bathymetric maps, we can immediately see that they indicate depths only up to a certain value previously referred to as the Extinction Depth. Satellite Bathymetry does not allow to determine the deeper depths and this is the main restriction of this method.

Although there are few, there are some applications for which satellite bathymetric maps may be useful. Despite the occurrence of differences between SDB results and correct depth indications, these maps retain the ability to present general bottom formation. This feature is quite important from the perspective of the need to control the changes in the bottom of the studied water body and prioritize the areas for reliable hydrographic survey in places where any fault in the proper bathymetry data delivery may result in a vessel grounding. If the bathymetric satellite map notices changes in the location or shape of the shoal, it can be assumed that the area requires examination by another, more accurate method, which would result in a possible update of the navigation maps.

Along with the previously presented possibilities of using bathymetric satellite maps, there are also restrictions, which, as it turns out, are much more numerous. They mainly result from the inaccuracy of the data received and the limitation of the area shown on the map to the Extinction Depth. This limit particularly affects the scope of application of satellite bathymetric maps. Depending on the body of water, the depth of disappearance in the Baltic Sea ranges from about 5 to 8 meters. This means that below such depth, satellite bathymetry does not distinguish between values, so it presents the bottom as a uniform area. The restriction is therefore the possibility of using these maps only in coastal waters, whose depths are smaller than the determined Extinction Depth. 
Weather conditions are another limitation affecting SDB. Pictures are taken by a satellite from a relatively high altitude, so any cloudiness over the photographed area affects the quality of the image received, and even causes its uselessness. The ratio of images affected by this phenomena for the Gulf of Gdańsk, achieved the level of 87\%. When trying to generate the bathymetric map, it may turn out that all available satellite images were taken in cloud conditions. Then it will be impossible to obtain the bathymetric map using SDB. In this case, photos taken from the deck of the aircraft may be much more useful, which, in the event of adverse conditions, may be under the lower layer of clouds.

Staying with the subject of environmental conditions, one should pay attention to the relationship between satellite bathymetry and the characteristics of water in a given body of water. In the case of Baltic, its low transparency is a major limitation, which is also caused by increasing pollution. Less possibility of light penetrating the water layers may result in the wave not reaching the bottom, which in turn causes incorrect determination of the depth at this point. The dark color of the water is also affected by the periodic occurrence of various types of vegetation, which can give the confusing impression of shallow areas.

The usability of Satellite Derived Bathymetry products is also affected by the low resolution of available imagery. The resolution of Landsat 8 imagery is $30 \mathrm{~m}$, which allows using only to general analysis of a given area, without resolving any minor features.

\section{CONCLUSIONS AND THE DIRECTIONS OF FURTHER RESEARCH}

The SBD method has a significant advantages. The large footprint of $185 \mathrm{~km}$ provide a lot of useful data. The method is repeatable, easily accessible and can be used as an alarm to pay attention for a specific areas There are some drawbacks in the method described and used in the paper, that make it limited and dependent on many factors. Many of them are independent of the user and cause that obtaining accurate bathymetric data for a given moment may not be possible. Therefore restrictions associated with cloud coverage of the analyzed area could be eliminated by using images of sea areas taken by Unmanned Aerial Vehicles (UAV). Their operational altitude is between 10 and 150 meters. This altitude is significantly below the cloud layer. Taking such measurements also results in a significant increase of the accuracy and resolution of the acquired imagery. Mostly aerial photos from unmanned 
aerial vehicles have a resolution of a few centimeters per pixel. Such accuracy translates into a much higher number of measurements per study area and increases the potential range of use.

However, the UAV method also has some limitations that must be indicated. First of all, the limited range and short battery life of the UAV battery will certainly cause that the waters far away from the operator (shore, beach) cannot be covered with aerial photographs. Another issue that needs to be highlighted is the limited possibility of georeferencing of aerial photographs taken over sea areas (reservoirs). To obtain high accuracy of position coordinates projected on a photograph (matrix of pixels), it would be necessary to carry out a georeference procedure using a high accuracy GNSS receiver (using RTK corrections) and a fixed infrastructure. These elements must be easily distinguishable in aerial photographs and assigned to the coordinates of their positions. Examples of two possible cases are presented in fig. 9.

The use of single aerial photographs may be a big limitation to the proposed method due to the low coverage of the sea area in the photograph and the need for georeferencing. The use of an orthophoto map of a coastal area made up of many interrelated aerial photos can solve the problems mentioned above. However, one should be aware that in the sea area the accuracy of position coordinates of particular points on the study will be degraded. Another restriction is associated with the process of building an aerial orthophoto map. This method is based on a combination of overlapping photos based on a search of their common elements (found on both or more photos). The common area (overlap) is interpolated on the basis of many photographs in which it is distinguishable. The indicated estimation may interfere with the real colors of individual points of the environment, because the photographs used in the process are not taken at the same time. An example is presented in fig. 10.

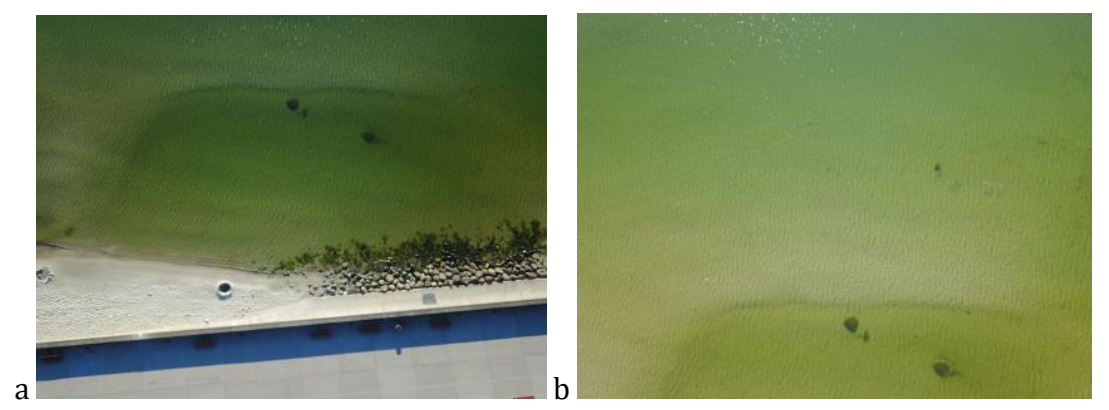

Fig. 9. (a) Part of the Gulf of Gdańsk, which can be georeferenced; (b) Part of the Gulf of Gdańsk which cannot be georeferenced due to no distinguishable objects or infrastructure 


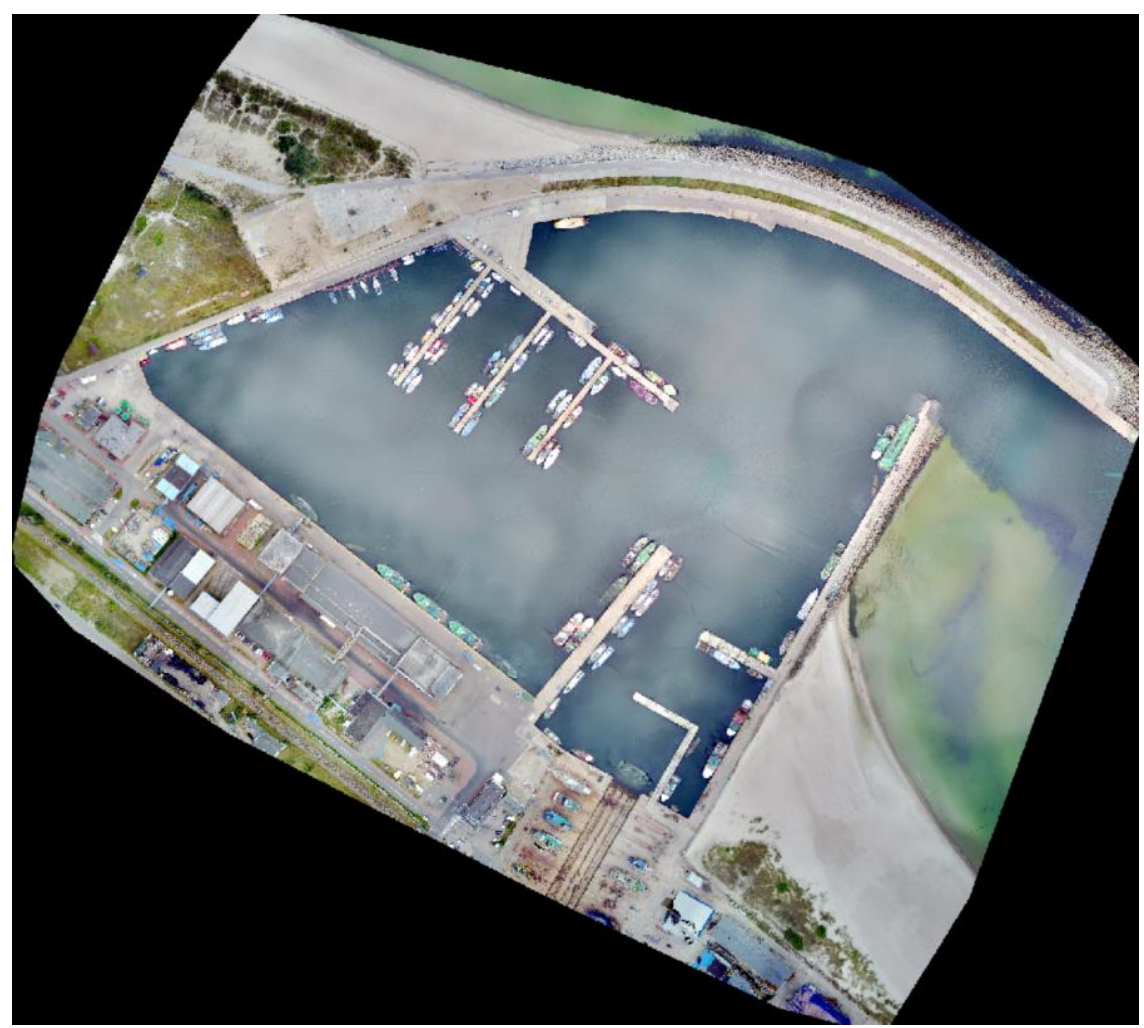

Fig. 10. Władysławowo harbour orthophoto map — many imperfections situated on the water surface

The UAV method's characteristic induce them to be used only in internal waters and coastal waters, where the land infrastructure exists at short distances (which can be used in the georeferencing process). However, from the point of view of the content presented in the paper, it seems justified to verify the assumptions presented here in the further work.

Overall, the SDB technique has many advantages as a reconnaissance tool for charts update, chart adequacy control and for risk assessment. The integration of different methods, for example the SDB method with the UAV, can lead to the accurate result, sufficient for continues shallow areas monitoring.

\section{Acknowledgments}

This work has been funded by the Polish Naval Academy statutory funds for young researchers. 


\section{REFERENCES}

[1] Biuro Hydrograficzne Marynarki Wojennej, Locja Bałtyku 502, Gdynia 2008 [Sailing Directions. Balitic Pilot — available in Polish].

[2] Chybicki A., Mapping South Baltic Near-shore bathymetry using Sentinel-2 observations, 'Polish Maritime Research', 2017, Vol. 24, No. 3 (95), pp. 15-25, DOI: 10.1515/pomr-2017-0086.

[3] Department of the Interior U.S. Geological Survey, Landsat 8 (L8) Data Users Handbook, Version 5.0, November 2019.

[4] Håkanson L. (ed.), Charakterystyka fizycznogeograficzna zlewiska Morza Bałtyckiego [The physical and geographical characteristics of Baltic Sea watershed], trans. A. Jankowski, G. Jankowski, 'Środowisko Morza Bałtyckiego', 1991, 1.

[5] International Hydrographic Organization, Intergovernmental Oceanographic Commission, The IHO-IOC GEBCO Cook Book, IHO Publication B-11, Monaco, Sep. 2018, 416 pp - IOC Manuals and Guides 63, France, September 2018.

[6] Leppäranta M., Myrberg K., Physical Oceanography of the Baltic Sea, 2009, Springer.

[7] Lyzenga D., Passive Remote-Sensing Techniques for Mapping Water Depth and Bottom Features, 'Applied Optics', 1978, Vol. 17, Issue 3, pp. 379-383, DOI: 10.1364/A0.17.000379.

[8] Lyzenga D., Malinas N., Tanis F. J., Multispectral bathymetry using a simple physically based algorithm, 'IEEE Transactions on Geoscience and Remote Sensing', 2006, Vol. 44, Issue 8, pp. 2251-2259, DOI: 10.1109/TGRS.2006.872909.

[9] Lyzenga D., Remote sensing of bottom reflectance and water attenuation parameters in shallow water using aircraft and LANDSAT data, 'International Journal of Remote Sensing', 1981, Vol. 2, pp. 71-82, DOI: 10.1080/01431168108948342.

[10] Pe'eri S., Freire R., Klemm A., Nyberg J., Satellite-Derived Bathymetry: Performance and Production, 2016, Canadian Hydrographic Conference, May 16-19, 2016 Halifax, NS.

[11] Pe'eri S., Madore B., Nyberg J., Snyder L., Parrish C., Smith S., Identifying Bathymetric Differences over Alaska's North Slope using a Satellite-derived Bathymetry Multi-temporal Approach, 'Journal of Coastal Research', 2016, No. 76 (sp 1), pp. 56-63, DOI: 10.2112/SI76-006.

[12] Pe'eri S., Parrish C., Azuike C., Alexander L., Armstrong A., Satellite Remote Sensing as Reconnaissance Tool for Assessing Nautical Chart Adequacy and Completeness, 'Marine Geodesy', 2014, Vol. 37, Issue 3, pp. 293-314, DOI: 10.1080/01490419.2014.902880.

[13] Philpot W., Bathymetric mapping with passive multispectral imagery, 'Applied Optics', 1989, Vol. 28., Issue 8, pp. 1569-1578, DOI: 10.1364/A0.28.001569.

[14] Stumpf R., Holderied K., Sinclair M., Determination of water depth with high resolution satellite imagery over variable bottom types, 'Limnology and Oceanography', 2003, Vol. 48, pp. 547556, DOI: 10.4319/lo.2003.48.1_part_2.0547.

[15] Sylvain J., Guillaume M., Minghelli-Roman A., Deville Y., Chami M., Lafrance B., Serfaty V., Hyperspectral remote sensing of shallow waters: Considering environmental noise and bottom intra-class variability for modeling and inversion of water reflectance, 'Remote Sensing of Environment', 2017, Vol. 200, pp. 352-367, DOI: 10.1016/j.rse.2017.08.020. 


\title{
DOSTEPNOŚĆ DANYCH OBRAZOWYCH LANDSAT 8 I MOŻLIWOŚĆ ICH WYKORZYTANIA W ALGORYTMACH BATYMETRII SATELITARNEJ DLA WÓD PRZYBRZEŻNYCH POŁUDNIOWEGO BAŁTYKU NA PRZYKŁADZIEZATOKI GDAŃSKIEJ
}

\section{STRESZCZENIE}

W artykule przedstawiono analizę dostępności i użyteczności zdjęć satelitarnych Landsat 8 na potrzeby generacji produktów batymetrii satelitarnej obszaru wód przybrzeżnych polskiego wybrzeża. Ogólne założenia SDB, programu Landsat i czynniki wpływające na proces wytwarzania produktów zostały szczegółowo opisane. Przykłady wyników SDB, wygenerowanych przy użyciu zarówno oprogramowania GIS, jak i Matlaba, przedstawiono na przykładzie wybranych akwenów Zatoki Gdańskiej. Zalety i wady metody oraz proponowane kierunki przyszłych prac przedstawiono w części podsumowującej.

Słowa kluczowe:

batymetria satelitarna, Landsat 8, sondaż batymetryczny.

\author{
Article history \\ Received: $\quad 04.03 .2020$ \\ Reviewed: 15.04.2020 \\ Revised: $\quad 19.04 .2020$ \\ Accepted: 28.04.2020
}

